\title{
Costs and benefits of a second measles inoculation of children in Israel, the West Bank, and Gaza
}

\author{
G M Ginsberg, T H Tulchinsky
}

\begin{abstract}
Study objective-Measles has been targeted by the WHO as a disease which should be eradicated. Use of existing vaccines during infancy has resulted in a substantial decline in cases in Israel, the West Bank, and Gaza. However the disease continues to occur in epidemic waves with large scale morbidity and mortality in all of these populations. This paper estimates the costs and benefits of three alternative strategies of adding immunisation at school age, and during young adult life to the present vaccination at 15 months.

Measurements and main results-A policy of immunising all Israeli children aged 6 (option A) would cost around $\$ 1$ million and have estimated benefits of $\$ 4.5$ million, yielding a benefit cost ratio of 4.53/1. Despite relatively lower medical care costs and work absence costs (as a result of the lower per capita GNP and lower female participation rate in the workforce), the West Bank and Gaza situations yield benefit to cost ratios of $5 \cdot 74 / 1$ and $9 \cdot 59 / 1$ respectively because of their relatively higher incidence rates. If implemented in Israel, a vaccination programme (such as option $A$ ) would prevent, over the next 10 years, approximately 28700 simple cases, 3400 hospital admissions, eight non-fatal cases of encephalitis, and $2 \cdot 2$ cases of SSPE. It would save 28 lives. The adoption of option $A$, is expected to reduce incidence and mortality by around 13600 and 32 cases in the West Bank, and by 18000 and 64 cases in Gaza.

Conclusion-The adoption of a two dose policy appears to be economically justifiable.
\end{abstract}

The eradication of measles by the year 2000 has been declared to be a major health target by the European World Health Organization. ${ }^{1}$ This is of special public health significance in developing countries, where measles remains one of the largest killers of children, ${ }^{23}$ resulting in more than 1.5 million deaths each year. ${ }^{4}$ Furthermore, measles complications are frequent and result in revelopmental retardation, lifelong handicaps, and both direct and indirect economic losses. ${ }^{5}$

Childhood immunisation in Israel is the responsibility of the Minister of Health. In Gaza and the West Bank, immunisation is the responsibility of the Government Health Services, part of the Israeli Civil Administration, and of UNRWA for residents of refugee camps. Reporting of infectious diseases is required by law in all three of the areas.
Immunisation against measles of infants at age nine months began in Israel in April, 1967, with live attenuated vaccine. Coverage in 1970 was reported to be $78 \%$ of the eligible infant population. ${ }^{67}$ In 1971, the age of administration was changed to 15 months, and in 1975, the imported vaccine Attenuvax was adopted. ${ }^{7}$ Immunisation coverage has increased from $82^{\circ} \%$ of children under two in 1980 to $88 \%$ in $1986 .^{8}$ Immunisation against measles began in the West Bank and Gaza in 1977 for infants at age nine months, with the same vaccine as used in Israel. Participation rates were low in the first several years, as compared to acceptance of other vaccines, but have reached $85-90 \%$ since the early 1980 s. $^{8}$ Measles, mumps and rubella (MMR) vaccine replaced the measles vaccine in 1986 in the West Bank and Gaza, and in 1989 in Israel.

Immunisation strategies for measles in most countries have focused in infancy (between 9 and 15 months), with some countries requiring school age proof of immunisation in order to increase the herd immunity and individual protection. However, some countries have used a two dose policy-in infancy and early school age. This article examines the benefits and costs of an expanded programme based on a school age vaccination compared to the present infancy immunisation programme in Israel, the West Bank, and Gaza.

\section{Morbidity and mortality}

As a result of measles vaccination in the routine infant immunisation programme with vaccination coverage in the $85-90 \%$ range, ${ }^{6}$ annual incidence rates in Israel have declined by $45.5 \%$ over the period 1968-1987 from 50.1 to $27 \cdot 3$ per 100000 . For the period from 1978 to November 221988 there were 47 reported deaths from measles, as compared to 115 in the period 1968-1977, a decline of $59 \% \cdot{ }^{9-12}$ The case fatality ratio of $6 / 1000$ in 1973 , rose to a peak of $10 / 1000$ in $1983 / 1984$ and declined to $3 / 1000$ in $1985 / 86$. In the West Bank and Gaza there has also been a substantial decline in the incidence of measles. However mortality from measles still remains a substantial problem in these regions, where 40 and 87 measles deaths respectively were reported during the period 1981-1987. (Judea and Samaria Government Health Statistics Division and Gaza Health Services Research Centre, unpublished data.)

In contrast, the USA and other countries have established firm control and near eradication of measles. The USA for example has achieved a $93 \%$ decline in incidence, from 19.9 in 1968-72 to $1 \cdot 4 / 100000$ in $1983-87$. Israel experienced an 
average annual death rate from measles of $0.9 / 100000$ population during the period 1980 86 , over 100 times the USA death rate of 0.008 / 100000 between 1980 and $1987 .^{1314}$

\section{Alternative strategies}

Israel's relatively poorer performance is a result of the current limitations on immunity levels in Israel (the West Bank and Gaza) caused by the $90 \%$ (as opposed to $100 \%$ ) coverage in infancy, as well as the primary failure rate. Evidence of this failure rate can be found in the approximately $20 \%$ reported cases in the 1986 epidemic in Israel that occurred in children with a documented history of past immunisation. ${ }^{15}$

In each annual cohort of 100000 Israeli and 55000 West Bank and Gaza infants, induced immunity occurs in only $80-85 \%$, leaving $15-20 \%$ of each cohort unprotected. Over the years, this group adds up to a substantial number of susceptible persons, providing a large population for continued circulation and transmission of the disease. In addition, since Israeli children were not immunised prior to 1966, and in the West Bank and Gaza not prior to 1976, persons over 12 and 22 years of age respectively remain susceptible, except for those who acquire natural immunity by acquiring the disease itself. Furthermore because of close contact in the population groups, cases and outbreaks in all three areas affect each other in transmission of the disease.

Globally, immunisation rates against measles are only around $50 \% .{ }^{16}$ Current stress in measles elimination strategy is being placed on expanding immunisation coverage in susceptible groups and epidemiological methods of case outbreak control. ${ }^{17}$ Recent evidence from Canada ${ }^{18}$ found that in addition to a $6 \%$ primary failure rate, a further $5 \%$ of people who were vaccinated against measles later exhibited declining antibody levels (secondary failures). This evidence supports the call for a policy of a second booster dose in order to reduce susceptibility to sufficiently low levels to allow the goal of measles elimination to be achieved.

Several countries (Sweden, Finland, Norway, Czechoslovakia) have already adopted a two dose measles immunisation policy to prevent the build up of susceptible populations at older ages due to an estimated $10 \%$ primary failure (failure to seroconvert) of present vaccines, combined with the problem of achieving more than $95 \%$ coverage. ${ }^{61920}$ Many developed countries have succeeded, during the last two decades, in reducing reported measles incidence and death rates to very low levels, ${ }^{1920}$ including some where immunisation coverage during infancy does not reach the level achieved in Israel, the West Bank, and Gaza. Canada has experienced a $97 \%$ decline in case incidence rates since 1963. This has occurred with only $83 \%$ infant immunisation coverage by high levels of school age coverage. ${ }^{21}$ Despite this, small scale outbreaks still occur and the stress in measles elimination strategy is being placed on case outbreak control epidemiology. ${ }^{21}$ In the United States, where measles vaccination was introduced in 1963, vaccination coverage in the second year of life is estimated at only $77 \%$.
The US has, however, implemented mandatory measles or MMR vaccination in all 50 states for school and army entry at all ages, so that the pool of susceptible individuals at older ages has been markedly reduced. ${ }^{21}$ The US programme of mandatory school age immunisation, started in 1977 , produces nearly $100 \%$ coverage of the very large school age population, which otherwise would constitute the largest vulnerable population. ${ }^{21}$ As a result, the disease has virtually been eradicated in the United States, except for sporadic small outbreaks associated with imported cases. ${ }^{19}$ This has resulted in the Israeli average measles incidence rate in the period 1982-87 being higher than that of the United States in the period 1968-72.

\section{Benefits and costs of a new strategy}

The situation of continued measles morbidity and mortality in Israel, the West Bank, and Gaza provides strong justification for a review and revision of present measles control policy. Israel has undertaken an international commitment to this important public health target, and therefore needs to develop appropriate strategies to fulfil this worthy goal.

Any programme to eradicate measels requires an expansion of the present immunisation programme. ${ }^{6}$ A two dose measles immunisation policy will be required in order to establish firm control, and almost certainly for elimination of the disease. The difficulties of reaching $100 \%$ of infant coverage, and the less than $100 \%$ vaccine effectiveness, may require that a routine school age booster be instituted, along with case-control epidemiological methods in order to achieve the goal of measles eradication.

Previous cost-benefit studies of vaccination against measles only related to a first dose situation and found high benefit to cost ratios. ${ }^{22-27}$ This paper provides a cost-benefit analysis of the adoption of a policy of expanding the existing vaccination programme at 15 months to inoculate school children with a second dose of measles vaccine.

The incremental costs and benefits of the various options will take into account changing needs for ambulatory care, hospital admission, work absences, and mortality benefits from projected reductions in measles, and its complications such as encephalitis (with and without sequelae) and subacute sclerosing panencephalitis (SSPE) cases.

\section{BACKGROUND}

Measles cases are reported individually, based on clinical diagnosis, with or without laboratory confirmation by the attending physician, clinic, hospital or other health care institution. Data are collected in the epidemiology department, and the public health divisions, in the respective areas. For the period 1983-mid 1988, there were 6164 reported cases in Israel, 1713 in the West Bank, and 1994 cases reported in Gaza (based only on period 1983-1987).

Measles is usually characterised by a transient febrile illness; however, cases can be complicated by pneumonia, convulsions, postinfectious encephalitis and lethal SSPE. Side effects from 
immunisations include pneumonia, convulsions, brain damage, and even death. ${ }^{28}$

The three alternative expanded intervention programmes designed to eliminate the disease are based on various assumptions of time periods required for measles near elimination (on a linear trend to a level of just $1 \%$ of the 1983-1988 incidence levels) of four years (option C), five years (option B), and seven years (option A). These options are defined as follows:

Option A: Continued measles immunisation at 15 months plus a routine second measles immunisation at early school age, ie, children 6-7 years of age;

Option B: Option A plus a mass immunisation campaign of 7-17 year olds;

Option C: Option A plus a mass immunisation campaign of 7-27 year olds.

The projected costs and benefits which could follow the adoption of each of the above three options were estimated by calculating the reduction in incidence expected to occur during the period from 1988 to 1998 inclusive.

Baseline incidence rates were calculated by dividing the total number of reported cases in period 1983 to mid-1988 by the relevant population at risk. ${ }^{29}$ This resulted in rates of $25 \cdot 6 / 100000$ for Israeli Jews, 29.9/100 000 for Israeli non-Jews, 38.4/100 000 for the West Bank, and 75.5/100 000 in Gaza (based just on the period 1983-1987).

Estimates of notification rates ${ }^{8}$ of $29 \%$ of cases for Jews and $17 \%$ of cases for non-Jews in Isreal were used to adjust the reported incidence rates to estimates of the true incidence rates. It was

Table I Expected incidence of measles, and its complications by immunisation strategy (1988-1998)

\begin{tabular}{|c|c|c|c|c|c|}
\hline & $\begin{array}{l}\text { Israel } \\
\text { fews }\end{array}$ & $\begin{array}{l}\text { Israel } \\
\text { Non-fews } \\
\end{array}$ & $\begin{array}{l}\text { Israel } \\
\text { Total }\end{array}$ & West Bank & Gaza \\
\hline $\begin{array}{l}\text { No change } \\
\text { Simple } \\
\text { Hospital } \\
\text { Encephalitis } \\
\text { Encephalitis + } \\
\text { SSPE } \\
\text { SS-mortality } \\
\text { N-s mortality }\end{array}$ & $\begin{array}{r}31739 \\
3587 \\
6 \cdot 7 \\
2.8 \\
7.4 \\
7.4 \\
9.5\end{array}$ & $\begin{array}{r}13761 \\
1787 \\
2 \cdot 9 \\
1 \cdot 2 \\
9 \cdot 0 \\
9 \cdot 0 \\
32 \cdot 4\end{array}$ & $\begin{array}{r}45500 \\
5375 \\
9.6 \\
4.0 \\
16 \cdot 4 \\
16.4 \\
41.9\end{array}$ & $\begin{array}{r}19133 \\
2484 \\
4 \cdot 0 \\
1 \cdot 7 \\
12.6 \\
12.6 \\
47.9\end{array}$ & $\begin{array}{r}25257 \\
3280 \\
5 \cdot 3 \\
2 \cdot 2 \\
16 \cdot 6 \\
16 \cdot 6 \\
98 \cdot 1\end{array}$ \\
\hline $\begin{array}{l}\text { Option } A \\
\text { Simple } \\
\text { Hospital } \\
\text { Encephalitis } \\
\text { Encephalitis + } \\
\text { SSPE } \\
\text { SS-mortality } \\
\text { N-s mortality }\end{array}$ & $\begin{array}{r}11743 \\
1327 \\
2.5 \\
1.0 \\
6.4 \\
6.4 \\
3.5\end{array}$ & $\begin{array}{r}5091 \\
661 \\
1.1 \\
0.4 \\
7.8 \\
7.8 \\
12.0\end{array}$ & $\begin{array}{r}16835 \\
1989 \\
3.5 \\
1.5 \\
14 \cdot 2 \\
14 \cdot 2 \\
15.5\end{array}$ & $\begin{array}{r}7079 \\
919 \\
1.5 \\
0.6 \\
10.9 \\
10.9 \\
17.7\end{array}$ & $\begin{array}{r}9345 \\
1213 \\
2 \cdot 0 \\
0 \cdot 8 \\
14 \cdot 3 \\
14 \cdot 3 \\
36 \cdot 3\end{array}$ \\
\hline $\begin{array}{l}\text { Option B } \\
\text { Simple } \\
\text { Hospital } \\
\text { Encephalitis } \\
\text { Encephalitis + } \\
\text { SSPE } \\
\text { SS-mortality } \\
\text { N-s mortality }\end{array}$ & $\begin{array}{r}7866 \\
889 \\
1 \cdot 7 \\
0 \cdot 7 \\
5 \cdot 8 \\
5 \cdot 8 \\
2 \cdot 4\end{array}$ & $\begin{array}{r}3410 \\
443 \\
0 \cdot 7 \\
0 \cdot 3 \\
7 \cdot 1 \\
7 \cdot 1 \\
8 \cdot 0\end{array}$ & $\begin{array}{r}11276 \\
1332 \\
2.4 \\
1.0 \\
12.9 \\
12.9 \\
10.4\end{array}$ & $\begin{array}{r}4742 \\
616 \\
1.0 \\
0.4 \\
9.9 \\
9.9 \\
11.9\end{array}$ & $\begin{array}{r}6259 \\
813 \\
1.3 \\
0.5 \\
13 \cdot 1 \\
13 \cdot 1 \\
24.3\end{array}$ \\
\hline $\begin{array}{l}\text { Option C } \\
\text { Simple } \\
\text { Hospital } \\
\text { Encephalitis } \\
\text { Encephalitis + } \\
\text { SSPE } \\
\text { SS- mortality } \\
\text { N-s mortality }\end{array}$ & $\begin{array}{r}5973 \\
675 \\
1.3 \\
0.5 \\
5.4 \\
5.4 \\
1.8\end{array}$ & $\begin{array}{r}2589 \\
336 \\
0.5 \\
0 \cdot 2 \\
6 \cdot 6 \\
6 \cdot 6 \\
6 \cdot 1 \\
\end{array}$ & $\begin{array}{r}8562 \\
1011 \\
1.8 \\
0.7 \\
11.9 \\
11.9 \\
7.9\end{array}$ & $\begin{array}{r}3600 \\
468 \\
0 \cdot 8 \\
0 \cdot 3 \\
9 \cdot 2 \\
9 \cdot 2 \\
9 \cdot 0 \\
\end{array}$ & $\begin{array}{r}4753 \\
617 \\
1 \cdot 0 \\
0 \cdot 4 \\
12 \cdot 1 \\
12 \cdot 1 \\
18.5 \\
\end{array}$ \\
\hline
\end{tabular}

Note: Encephalitis + denotes non-fatal encephalitis cases with sequelae Encephalitis denotes non-fatal encephalitis cases without sequelae assumed that the percentage of cases notified in the West Bank and Gaza was the same as for non-Jews in Israel.

These rates were applied to national population estimates to simulate incidence rates of measles for the years 1988-1998 in the absence of any second measles vaccination programme. In such a situation it is estimated there would be 50914 cases of measles in the Israeli population (35 326 among Jews) during the period 1988-1998 (21 617 in the West Bank and 28537 in Gaza).

Next the estimated true incidence rates were applied in turn to the various vaccination options. Under Option A, there would be a decrease of $67.0 \%$ in the number of measles cases to 18823 in Israel (7998 in the West Bank and 10558 in Gaza). Using Option B there would be a decrease of $75.2 \%$ to 12608 cases in Israel (5358 in the West Bank and 7072 in Gaza). Option C would lead to a decrease of $81.2 \%$ in the number of measles cases to 9573 in Israel (4068 in the West Bank and 5370 in Gaza) (table I).

The number of hospital admissions was calculated by applying the age and ethnic group specific probabilities of a reported case being admitted to hospital in 1979 , being 0.35 for Jews and 0.68 overall for non-Jews, ${ }^{30}$ to the estimated number of reported cases. If Option A were adopted, then the number of cases requiring hospital admission would drop from 5375 to 1989 during 1988-1998. By 1994, there would be around 484 fewer hospital admissions annually for measles, saving around 2000 hospital days a year or six fully occupied beds.

Case mortality rates from non-SSPE measles related deaths were calculated by dividing the total deaths for the period $1976-1987$ by the total number of notified cases during the same time period. The notified case fatality rate of $0.087 \%$ for Israeli Jews was considerably higher than the rate for non-Jews in Israel $(1 \cdot 22 \%)$, the West Bank $(1.30 \%)$, or Gaza $(2.01 \%)$. These case fatality differences might not only arise from differences in home or health service care but may also be due to differences in reporting rates in the different communities. During the study period, non-SSPE mortality rates in Israel would fall from 42 to 15.5 cases if Option $A$ were adopted (to 10.4 cases for Option B, and to 7.9 cases under Option C).

\section{SECONDARY ILLNESSES}

Reduction in the incidence of secondary illnesses would also follow as a result of a second vaccination programme. Figures of $2 \cdot 1$ and 1.4 per $10000^{13} 31$ were used in our analysis as an estimate of the incidence of measles encephalitis without and with sequelae respectively. The case fatality rate was assumed to be $15 \%{ }^{27}$ In Israel, under Option $A$, the total number of encephalitis cases would fall from 13.6 to 5 cases (to 3.4 cases under Option B and to 2.5 cases under Option C) (table I). For SSPE, a figure of 2.32 per 10000 cases was used for the Israeli Jewish population and 6.57 per 10000 cases for the non-Jewish populations of Israel, the West Bank, and Gaza. ${ }^{8}$ SSPE occurs on average around seven years after the measles onset and all known cases reported in the 1964-1969 period were under 10 years of age. ${ }^{8}$ The fall in the number of SSPE cases will be of the 
same magnitude as the decrease in all encephalitis cases (see table I). WHO figures estimate that pneumonia occurs as a result of measles in around $5 \%$ of all cases, convulsions in $0.072 \%$ of cases, and brain damage in $0.028 \%$ of cases. ${ }^{28}$

\section{COST ESTIMATES}

Estimates of cost per case are listed in the table II, which also divides the total cost into its health service components (hospital costs and ambulatory clinic costs including medication) and work losses. The methodology of the calculations is described below for Israeli Jews.

Simple cases (with common complications)

For simple cases of measles, it is assumed that an ambulatory visit will be made related to symptoms of high fever and/or coughing, with a second visit to confirm the rash. In addition cases with commonly associated complications as otitis media, mastoiditis, laryngitis and respiratory infections ${ }^{31} 32$ will require further ambulatory visits. Therefore 2.2 (15 min) ambulatory visits which cost $\$ 8.80$ are assumed (physician wage costs $\$ 16$ per hour). In addition, a conservative estimate of $3 \%$ of cases are estimated to require a physician visit to the home taking $\mathbf{4 0} \mathrm{min}$ including travelling time. This results in a unit cost of $\$ 10.66$ for a home visit, or $\$ 0.32$ per simple measles case. Medication (mostly antibiotics and antipyretics) was assumed to be required in $30 \%$ of the cases at a unit cost of $\$ 8$ per course, or $\$ 2.40$ per measles case. Adult work losses were calculated by multiplying the age and sex specific participation rates (being overall $93 \%$ for males and $70 \%$ for females) in the labour force by the age and sex specific wage costs (being overall

Table II Estimates of costs and probabilities of complications from measles (Israel, West Bank and Gaza 1988-1998). Prob= probability

\begin{tabular}{|c|c|c|c|c|}
\hline & Fews & Non-feros & $\not{f u d}+S A$ & Gaza \\
\hline $\begin{array}{l}\text { Simple case } \\
\text { Prob per case } \\
\text { ambulatory costs } \\
\text { work losses } \\
\text { Total cost }\end{array}$ & $\begin{array}{r}1 \\
\$ 12 \\
\$ 129 \\
\$ 141\end{array}$ & $\begin{array}{r}1 \\
\$ 12 \\
\$ 56 \\
\$ 68\end{array}$ & $\begin{array}{r}1 \\
\$ 8 \\
\$ 10 \\
\$ 19\end{array}$ & $\begin{array}{r}1 \\
\$ 8 \\
\$ 4 \\
\$ 13\end{array}$ \\
\hline $\begin{array}{l}\text { Hospital cases: ( } 100 \% \text { repo } \\
\text { Prob per case reported } \\
\text { ambulatory costs } \\
\text { hospital costs } \\
\text { work losses } \\
\text { Total cost }\end{array}$ & $\begin{array}{r}0.35 \\
\$ 16 \\
\$ 873 \\
\$ 197 \\
\$ 1086\end{array}$ & $\begin{array}{r}0.68 \\
\$ 16 \\
\$ 726 \\
\$ 96 \\
\$ 838\end{array}$ & $\begin{array}{r}0.68 \\
\$ 12 \\
\$ 533 \\
\$ 5 \\
\$ 551\end{array}$ & $\begin{array}{r}0.68 \\
\$ 12 \\
\$ 533 \\
\$ 1 \\
\$ 546\end{array}$ \\
\hline $\begin{array}{l}\text { Measles encephalitis } \\
\text { Prob per case } \\
\text { ambulatory costs } \\
\text { hospital costs } \\
\text { work losses } \\
\text { Total cost }\end{array}$ & $\begin{array}{r}0.00021 \\
\$ 85 \\
\$ 2609 \\
\$ 394 \\
\$ 3088\end{array}$ & $\begin{array}{r}0.00021 \\
\$ 85 \\
\$ 2609 \\
\$ 192 \\
\$ 2886\end{array}$ & $\begin{array}{r}0.00021 \\
\$ 76 \\
\$ 1957 \\
\$ 10 \\
\$ 2044\end{array}$ & $\begin{array}{r}0.00021 \\
\$ 76 \\
\$ 1957 \\
\$ 1 \\
\$ 2035\end{array}$ \\
\hline $\begin{array}{l}\text { Measles encephalitis }+ \text { seque } \\
\text { Prob per case } \\
\text { ambulatory costs } \\
\text { hospital costs } \\
\text { work losses } \\
\text { Total cost }\end{array}$ & $\begin{array}{r}0.0000875 \\
\$ 16 \\
\$ 35676 \\
\$ 590 \\
\$ 36282\end{array}$ & $\begin{array}{r}0.000087 \\
\$ 16 \\
\$ 35676 \\
\$ 288 \\
\$ 35979\end{array}$ & $\begin{array}{r}0.000087 \\
\$ 12 \\
\$ 11058 \\
\$ 16 \\
\$ 11086\end{array}$ & $\begin{array}{r}0.000087 \\
\$ 12 \\
\$ 6982 \\
\$ 2 \\
\$ 6996\end{array}$ \\
\hline $\begin{array}{l}\text { SSPE } \\
\text { Prob per case } \\
\text { ambulatory costs } \\
\text { hospital costs } \\
\text { work losses } \\
\text { Total cost }\end{array}$ & $\begin{array}{r}0.000232 \\
\$ 16 \\
\$ 9269 \\
\$ 523 \\
\$ 9808\end{array}$ & $\begin{array}{r}0.000657 \\
\$ 16 \\
\$ 9269 \\
\$ 255 \\
\$ 9540\end{array}$ & $\begin{array}{r}0.000657 \\
\$ 12 \\
\$ 6952 \\
\$ 14 \\
\$ 6978\end{array}$ & $\begin{array}{r}0.000657 \\
\$ 12 \\
\$ 6952 \\
\$ 2 \\
\$ 6966\end{array}$ \\
\hline Mortality - gnp & $\$ 76518$ & $\$ 76518$ & $\$ 21061$ & $\$ 11628$ \\
\hline $\begin{array}{l}\text { Non-SSPE mortality costs } \\
\text { Prob per case }\end{array}$ & 0.00092560 & 0.012258 & 0.013035 & 0.020212 \\
\hline Mortality —enp & $\$ 76098$ & $\$ 76587$ & $\$ 21080$ & $\$ 11639$ \\
\hline
\end{tabular}

$\$ 54.48$ per day for males and $\$ 30.96$ per day for females). ${ }^{29}$ This product was then multiplied by the number of working days missed through illness $(4 \cdot 71$, being $5 \cdot 5 / 7$ of the estimated six day period the adult is expected to be ill at home). Child work losses were of course zero; however an addition was made for the work losses incurred by a parent (assumed female) who was conservatively assumed to be at home for nine days ( 7.07 working days) to care for her child. ${ }^{31}$ The age specific participation rate used was only $51.9 \%$, reflecting the younger age group of females when compared to the adult female measles victims. Overall the average work loss per case amounted to $\$ 129 \cdot 27$, considerably higher than the average health service costs of $\$ 11.52$ per case.

\section{Complicated cases}

For cases requiring hospital admission, it was assumed that there would be 2.5 (15 $\mathrm{min}$ ) ambulatory or emergency room visits (costing $\$ 10$ per case), and a home visit in 3\% of the cases (costing $\$ 0.32$ per case); and that $70 \%$ of cases would require medication (costing $\$ 5.60$ per case). Non-hospital health service costs totalled around $\$ 16.00$ per case. The average length of hospital stay was estimated to be 3.03 days for persons aged 16 or over and 5.66 days for children under 16 years, being $90 \%$ and $80 \%$ of the latest available data from $1979 .{ }^{30}$ The age-specific mix of hospitalised cases $(43.4 \%$ aged $18+, 6.4 \%$ aged $16-17$, and $50 \cdot 2 \%$ aged $0-15$ ) was applied to the above length of stays and muliplied by the average per diem hospital cost of $\$ 200.70$ in 1988 . Thus the overall average hospital cost for a case of measles amounts $\$ \mathbf{8 7 3} \cdot \mathbf{4 2}$. Work losses were calculated as described in the previous paragraph, based on the assumption that in addition to their 3.03 and 5.66 days in hospital, an adult or child would be at home for a further five and six days respectively. These totalled $\$ 196.76$ per average hospital admission for measles.

\section{Measles encephalitis}

For measles encephalitis cases, the assumed ambulatory, home visits, and medication costs were as for an otherwise uncomplicated hospital case $(\$ 15.92)$. However all cases were assumed to be admitted for seven days to a medical ward (costing $\$ 200.7$ per day) and for three days to an intensive care unit, assumed to cost double the average per diem cost. Therefore each measles encephalitis case costs around $\$ 2609$ in hospital fees. Work losses were assumed to be double those of an uncomplicated hospital admission for measles and amounted to $\$ 393$ per case. Three quarters of the cases were assumed not to have sequelae. These required a further four follow up ambulatory visits (\$16) and $\$ 53$ in tests, giving a total cost of $\$ 3103$ per case without sequelae.

For the $\mathbf{2 5 5}$ of cases with neurologic sequelae, work losses three times that of uncomplicated hospitalized measles case were assumed (\$590). In addition, costs of institutional care amounting to a discounted value of $\$ 33000$ were estimated. In addition a case fatality rate of $15 \%$ was assumed.

\section{SSPE}

Cases of SSPE were assumed to require two and a half ambulatory visits, need 90 days hospital 
admission (averaging $\$ 9269$ per case) and incur 60 days of work losses by each working mother (averaging $\$ 523$ per case).

\section{Mortality costs}

Costs of early mortality were based on 1979 data $^{33}$ which showed that the average age at death for non-SSPE cases to be two years for Jewish children and 37 for Jewish adults. For non-Jewish Israeli's the average age at death overall was two years, as no cases of adult mortality were recorded. For the West Bank and Gaza, age specific data on deaths from 1986-1988 were used. An average age of eight years old was assumed for SSPE cases in all the populations. ${ }^{8}$

Instead of valuing a person purely by his discounted expected future earnings (the Human Capital Method), the GNP per Head method assigns an equal value to everyone in society, equivalent to the Gross National Product per head ( $\$ 7666$ in $\left.1987^{29}\right)$. The GNP per HEAD method of economic valuation of life thereby overcomes the major shortcoming of the human capital method which perhaps unjustly assigns a zero value to childhood years, compulsory military service years, pensioners and housewives who are not in any direct remunerative employment. However, children, military personnel, housewives and pensioners (grandparents etc.) do certainly contribute something to society, be it the production of the next generation, the maintenance of the present workforce or just "tender loving care". Using a $10 \%$ discount rate, the net present values of Israeli persons were $\$ 76587, \$ 76518$ and $\$ 75120$ at ages two, eight and 37 respectively. The valuation of lives was considerably lower in the West Bank and Gaza due to the lower GNP per head in these areas. This points to a weakness in the GNP per head method, which still relates valuations of life to societal productivity. One could argue that a life in the West Bank, Gaza or Ghana should not be valued less than a life in Israel or Sweden.

\section{Programme costs}

Costs for vaccine related only to the material costs (\$1.60 per dose) since a secondary vaccination programme can be instituted within existing manpower and cold chain constraints.

Evidence of this excess labour capacity comes from: (1) The 1988 Israeli polio epidemic, in which over $90 \%$ of the 3 million population aged under 40 years old were inoculated within a six week period using existing public health system manpower; (2) The August 1989 decision taken in the West Bank and Gaza (aided by earlier drafts of this paper) to implement not only a second measles vaccination for children aged 8-12 years old, but also a second mumps and rubella vaccination to children aged 6-7 years old. This decision was taken without any mention or request for extra manpower to carry out the extra tasks.

Option A would require the vaccination of around 95000 six year olds each year in Israel, 26000 in the West Bank and 19000 in Gaza. Total costs (using a $10 \%$ discount rate, for costs incurred other than in the initial year of the project) amount to $\$ 955000$ in Israel, $\$ 154000$ in the West Bank and $\$ 108000$ in Gaza.
Option B would in addition (to the costs incurred under Option A) require a one-off vaccination programme in the first year of around $10000007-17$ year olds in Israel, 251000 in the West Bank and 170000 in Gaza. The total costs (discounted at $10 \%$ for costs incurred after the first year of the project) amount to $\$ 2.57$ million in Israel, $\$ 555000$ in the West Bank and $\$ 381000$ in Gaza.

The most expensive option is $\mathrm{C}$, which would annually immunise all six year olds and in addition conduct a one-off campaign to immunise 1.6 million persons aged 7-27 in Israel, 414000 in the West Bank and 272000 in Gaza. The total costs (using a $10 \%$ discount for costs incurred after the first year of the programme) amount to $\$ 3.59$ million in Israel, $\$ 817000$ in the West Bank and $\$ 545000$ in Gaza.

Pneumonia is only expected as a side effect of innoculation in one per 100000 persons, convulsions in six per 10000 persons, brain damage in one per million persons. ${ }^{28}$ The incidence of these side effects if a second vaccination were not to be carried out would be considerably higher. In order to simplify calculations, the costs of these side effects were omitted both from the costs of vaccination and from the benefits of vaccination. Since an early death as a result of a vaccination occurs in less than 1 in 10 million cases, this cost was omitted.

\section{Benefits (or averted costs)}

If vaccination is performed there will be a considerable reduction in measles during the period 1988-1997. Table I summarises the estimated reduction in uncomplicated ambulatory cases and hospital admissions and the expected reductions in the number of measles encephalitis cases (with and without sequelae), SSPE cases, and mortality resulting from nonSSPE cases.

The main monetary benefits of vaccination are the costs averted by caring for a reduced number of cases. Reductions in incidence were multiplied by the relevant unit costs per case, described earlier in this paper. The resultant benefits are listed in table III using a $10 \%$ discounted rate to calculate net present values of future benefits and costs.

In keeping with the conservative nature of our estimates, the cost of transport and time involved in visiting a person in hospital was omitted in the valuation of benefits. Also, it was assumed that parents accompanied children on ambulatory visits outside their working hours. Finally, no attempt was made to monetarise the benefits in such important but intangible dimensions as reduced pain, worry or grief.

\section{Cost-benefit analysis}

Table III shows that costs and benefits of three possible immunisation options for alternative measles eradication policies. Despite relatively lower medical care costs and work absence costs (as a result of the lower per capita GNP and lower female participation rate in the workforce), the West Bank and Gaza situations (5.74/1 and 9.59/1 for option A) show higher benefit to cost ratios than in Israel $(4.53 / 1)$ because of the relatively higher incidence rates. 
A policy of immunising all Israeli children aged 6 (option A) would cost around $\$ 1$ million and have estimated benefits of $\$ 4.50$ million, yielding a benefit to cost ratio of $4 \cdot 53 / 1$. Options $B$ and $C$ (costing \$2.57 million and \$3.59 million respectively) have lower benefit to cost ratios than option A. However, in all options, the benefits are greater than the costs over the time period 19881998. This finding is similar in the West Bank, but even more marked in the case of Gaza, where even the expensive option $C$, shows a benefit to cost ration of $2 \cdot 66 / 1$.

\section{Discussion}

The incremental benefits of instituting a second vaccine under Option $A$ exceed the incremental costs, giving a cost-benefit ratio of $4.53 / 1$ in Israel. However, the extra costs $(\$ 1.58 \mathrm{~m})$ of using Option B instead of Option A exceed the incremental benefits $(\$ 1 \cdot 15 \mathrm{~m})$, giving a benefit to cost ratio of only $0 \cdot 73 / 1$. Similarly, the costs of expanding from Option B to Option C $(\$ 1.02 \mathrm{~m})$ by far exceed the extra benefits $(\$ 0.62 \mathrm{~m})$, giving a benefit to cost ratio of only $0.61 / 1$.

Therefore, option A appears to be the most resource efficient strategy to use in the fight against measles. Even, if we assume that the secular downward trend from 1968-1985 in incidence rates would have continued into the future, then the benefit to cost ratio for option $\mathrm{A}$ still exceeds $3 \cdot 1 / 1$.

Benefits from reduced incidence in measles encephalitis and SSPE account for only a small percentage of the total benefits. Hence even if such gains have been grossly overestimated, the effect on the benefit to cost ratios will be small.

Even when only the benefits resulting from reductions in simple cases and cases admitted to hospital are considered, the benefit to cost ratio is still high: 3.39/1 in Israel, 3.51/1 in the West Bank and 6.07/1 in Gaza. Therefore any errors in the estimates of incidence or costs of encephalitis, SSPE or mortality have no significant effect on any policy recommendations based on the benefit to cost ratios.

Even if simple measles cases required only one ambulatory visit, no home visits, no medications and there was a $50 \%$ reduction in hospital length of stay (with an attendant reduction in the number of days lost from work) and a $33.3 \%$ reduction in hospital costs per day, the benefit to cost ratio in Israel under Option A would be 3.67/1. If, in addition, total days off work are reduced by $50 \%$, the benefit to cost ratio of $2 \cdot 80 / 1$ is still well above unity.

If the expected $99 \%$ reduction in annual measles incidence occurs for options $A, B$ and $C$ in 9,7 and 6 years instead of the 7,5, and 4 years, then the benefit to cost ratios for Option $A$ falls to $3.53 / 1$ in Israel, $4.88 / 1$ in the West Bank and to $8 \cdot 16 / 1$ in Gaza. For Option B the ratios are 1.54/1, $1.70 / 1$ and $2.92 / 1$ respectively, while for option $C$, they are 1.26/1, 1.29/1 and 2.28/1 in Gaza.

Vaccine costs would have to increase from $\$ 1.60$ to $\$ 7.23$ for overall costs to equal benefits under option $A$ in Israel. The break even point when just benefits to the health services are considered, would occur if vaccine costs were to rise to $\$ 2 \cdot 83$.

However, results are sensitive to changes in per capita GNP levels. For example, if the West Bank and Gaza were to reach the same level of per capita GNP as Israel (and by implication have similar medical costs), then the benefit to cost ratios for Option A would rise to $13 \cdot 6 / 1$ and $32 \cdot 0 / 1$ respectively. Conversely, GNP per capita levels would have to decrease drastically to starvation levels, before costs would approach benefits in the West Bank and Gaza.
Table III Benefit to cost ratio of various immunisation strategies: measles (Israel, West Bank and Gaza)

\begin{tabular}{|c|c|c|c|c|c|c|}
\hline & $\begin{array}{l}\text { Israel } \\
\text { costs } \\
\text { no vaccine }\end{array}$ & $\begin{array}{l}\text { Israel } \\
\text { costs } \\
\text { vaccine }\end{array}$ & $\begin{array}{l}\text { Israel } \\
\text { benefits }\end{array}$ & $\begin{array}{l}\text { Israel } \\
\text { benefit } \\
\text { to costs }\end{array}$ & $\begin{array}{l}\text { West Bank } \\
\text { benefit } \\
\text { to costs }\end{array}$ & $\begin{array}{l}\text { Gaza } \\
\text { benefit } \\
\text { to costs }\end{array}$ \\
\hline $\begin{array}{l}\text { Option } A \\
\text { Simple } \\
\text { Hospital } \\
\text { Encephalitis } \\
\text { Encephalitis + } \\
\text { SSPE } \\
\text { SSPE mortality } \\
\text { Non-SSPE mortality }\end{array}$ & $\begin{array}{r}\text { s } \\
3189926 \\
3184477 \\
17076 \\
85075 \\
93569 \\
741152 \\
1892498\end{array}$ & $\begin{array}{r}\text { S } \\
1501716 \\
1499150 \\
8039 \\
40050 \\
85159 \\
674539 \\
890928\end{array}$ & $\begin{array}{r}\text { s } \\
1688210 \\
1685326 \\
9037 \\
45024 \\
8410 \\
66612 \\
1001570\end{array}$ & $\begin{array}{l}1.70 \\
1.69 \\
0.01 \\
0.05 \\
0.01 \\
0.07 \\
1.01\end{array}$ & $\begin{array}{l}0.73 \\
2.78 \\
0.02 \\
0.04 \\
0.03 \\
0.09 \\
2.05\end{array}$ & $\begin{array}{l}0.91 \\
5.16 \\
0.03 \\
0.04 \\
0.05 \\
0.08 \\
3.29\end{array}$ \\
\hline Total costs & 9203773 & 4699580 & $\begin{array}{r}4504193 \\
995346\end{array}$ & 4.53 & 5.74 & $9 \cdot 59$ \\
\hline $\begin{array}{l}\text { Option B } \\
\text { Simple } \\
\text { Hospital } \\
\text { Encephalitis } \\
\text { Encephalitis + } \\
\text { SSPE } \\
\text { SSPE mortality } \\
\text { Non-SSPE mortality }\end{array}$ & $\begin{array}{r}3189926 \\
3184477 \\
17076 \\
85075 \\
93569 \\
741152 \\
1892498\end{array}$ & $\begin{array}{r}1080604 \\
1078758 \\
5785 \\
28819 \\
80417 \\
636961 \\
641094\end{array}$ & $\begin{array}{r}2109322 \\
2105718 \\
11292 \\
56255 \\
13152 \\
104191 \\
1251404\end{array}$ & $\begin{array}{l}0.82 \\
0.82 \\
0.00 \\
0.02 \\
0.01 \\
0.04 \\
0.49\end{array}$ & $\begin{array}{l}0.25 \\
0.96 \\
0.01 \\
0.01 \\
0.01 \\
0.04 \\
0.71\end{array}$ & $\begin{array}{l}0.32 \\
1.84 \\
0.01 \\
0.02 \\
0.03 \\
0.04 \\
1.17\end{array}$ \\
\hline Total costs & 9203773 & 3552435 & $\begin{array}{l}5651338 \\
2571904\end{array}$ & $2 \cdot 20$ & 2.00 & 3.43 \\
\hline $\begin{array}{l}\text { Option } C \\
\text { Simple } \\
\text { Hospital } \\
\text { Encephalitis } \\
\text { Encephalitis + } \\
\text { SSPE } \\
\text { SSPE mortality } \\
\text { Non-SSPE mortality }\end{array}$ & $\begin{array}{r}3189926 \\
3184477 \\
17076 \\
85075 \\
93569 \\
741152 \\
1892498\end{array}$ & $\begin{array}{r}855826 \\
854364 \\
4581 \\
22825 \\
76693 \\
607479 \\
507739\end{array}$ & $\begin{array}{r}2334100 \\
2330113 \\
12495 \\
62250 \\
16876 \\
133672 \\
1384759\end{array}$ & $\begin{array}{l}0.65 \\
0.65 \\
0.00 \\
0.02 \\
0.00 \\
0.04 \\
0.39\end{array}$ & $\begin{array}{l}0.19 \\
0.72 \\
0.00 \\
0.01 \\
0.01 \\
0.03 \\
0.53\end{array}$ & $\begin{array}{l}0.25 \\
1.42 \\
0.01 \\
0.01 \\
0.02 \\
0.04 \\
0.91\end{array}$ \\
\hline Total costs & 9203773 & 2929508 & $\begin{array}{l}6274266 \\
3592251\end{array}$ & 1.75 & 1.51 & 2.66 \\
\hline
\end{tabular}

All future costs and benefits have been discounted using a $10^{\circ}$. discount rate 
These sensitivity analyses show that for all the various options, the benefits appear to exceed costs. The net present value or the total savings (ie, excess of benefits over costs) from an inoculation programme in Israel alone are around $\$ 3.5$ million using option $\mathrm{A}, \$ 3.1$ million using option B, and $\$ 2.6$ million using option C.

Furthermore, the omission of the costs resulting from side effects of the vaccine and the omission of the larger benefits from a reduction in pneumonia, convulsions and brain damage as a result of a second vaccine programme, act to produce a downward bias in our cost-benefit ratios.

If implemented in Israel, a vaccination programme (such as option $A$ ) would prevent over the next 10 years, approximately 28700 simple cases, 3400 hospital admissions, 8.6 non-fatal cases of encephalitis, and $2 \cdot 2$ cases of SSPE, and save 28 lives.

All this can be gained at no extra cost to society, indeed a net saving of around $\$ 3.5$ million will accrue. About $\$ 1.76$ million of this will be savings to the health services, giving a benefit to cost ratio based only on health service benefits of around $1 \cdot 77 / 1$. This should not present a barrier to the implementation of a vaccination programme by health service agencies. Indeed, any enterprising sick fund would do well to initiate such a programme on its own as this would save the fund around $\$ 7700$ for each percentage of the population insured.

The adoption of Option $A$ is expected to reduce incidence and mortality by around 13600 and 32 cases in the West Bank, and by 18000 and 64 cases in Gaza.

The objective of measles elimination adopted by the WHO European Region necessitates a new strategy for using the excellent live attenuated vaccine currently available. The benefits of measles elimination in terms of reduced illness and death justify the expenditure required. Measles eradication is therefore an achievable goal, and a worthy challenge for public health in the 1990s in Israel. ${ }^{34}$ It is recommended that an immediate programme begin for inoculating schoolchildren at the age of six years. Parallel to this a population serosurvey should be conducted in order to provide information as to what the optimal age for a second vaccination should be. The initial protocols of vaccination at age six can in the future be adjusted in keeping with the recommendations of a parallel population serosurvey as to the optimal age for a second vaccination. Every month's delay in the implementation of a second-dose inoculation programme not only results in more measles cases, higher health service resource costs, and more lost productivity, but also in a potential loss of human lives.

We wish to thank Michael Shoenbaum and Julie Friedman (Sherut La'am Volunteers), for their assistance in this work. The opinions expressed in this article are those of the authors, and not necessarily of the Ministry of Health and the Government Health Services.

1 World Health Organization, Regional Office for Europe. Targets for health for all: Targets in support of the regional strategy for health for all. Geneva: WHO, 1986.

2 UNICEF. State of the world's children. New York: Oxford University Press, 1986.

3 Foege WH. Banishing measles from the world. World Health Forum 1984; 5: 63-4.

4 Assaad F. Measles: summary of worldwide impact. Review of infectious diseases 1985; 5: 452-9.

5 Hopkins DR, Hinman AR, Koplan JP, Lane JM. The case for global measles eradication. Lancet 1982; i: 1396-8.

6 Swartz TA. Prevention of measles in Israel: implications of a long term partial immunisation program. Public Health Rep 1984; 99: 272-7.

7 Ministry of Health. A review of health services in Fudea, and Samaria, and Gaza 1985-1986 16-17. Jerusalem.

8 Zilber N, Rannon L, Alter $M$ et al. Measles, measles vaccination and risk of subacute sclerosing Panencephalitis. Neurology 1983; 33: 1558-64.

9 Central Bureau of Statistics. Statistical tables on selected infections, 1965-1970. Special series no. 379. Jerusalem: Central Bureau of Statistics, 1972.

10 Central Bureau of Statistics. Statistical tables on selected infectious diseases 1971-1975. Special series no. 545. Jerusalem: Central Bureau of Statistics, 1977.

11 Central Bureau of Statistics. Statistical tables on selected infectious diseases 1976-1980. Special series no. 722. Jerusalem: Central Bureau of Statistics, 1983.

12 Central Bureau of Statistics. Statistical tables on selected infectious diseases 1981-1985. Jerusalem: Central Bureau of Statistics, in process.

13 Centers for Disease Control. Measles surveillance report No. 11 1977-1981 Atlanta CDC September 1982.

11 1977-1981 Atlanta CDC September 1982 .
14 United Nations Demographic Yearbook, 30-37 editions, New York: United Nations, 1980-1987.

15 Measles in Israel. Monthly Epidemiology Bull 1986; 22(2): 19-21.

16 Walgate $R$. Talloires, a quiet revolution. World Health 1988 : 28-9. (ISSN 0043-8502).

17 Walgate R. Progress towards achieving the national 1990 objectives for immunization. Morbidity Mortality Weekly Rev 1980; 37: 1-3. 18 Mathias RG, Meekson WG, Arcand TA, Schechter MT.
The role of secondary vaccine failures in measles outbreaks. Am $\Im$ Public Health 1989; 79: 475-8.

19 Frank JA, Orenstein WA, Bart KJ, Bart SW, El-Tantawy N, Davis RM, Hinman AR. Major impediments to measles elimination: the modern epidemiology of an ancient elimination: the modern epidemiology
disease. Am $\mathcal{F}$ Dis Child 1985; 139: 881-8.

20 Rabo E, Taranger J. Scandinavian model for elimination of measles, mumps, and rubella. $\mathrm{Br}$ Med $\mathcal{F}$ 1984: 289: 1402-4. measles, mumps, and rubella. Br Med f 1984: 289: 1402-4
Canada Diseases Weekly Rep Vol 15; 1, 7 January 1989.

21 Canada Diseases Weekly Rep Vol 15; 1, 7 January 1989. Witte JJ, Axnick NW. The benefits from 10 years of measles
immunization in the United States. Public Health Reports 1975; 90: 205-7.

23 Albritton RB. Cost-benefits of measles eradication: effects of a federal intervention. Policy Analysis 1978; 4: 1-22.

24 Axnick NW, Shavell SM, Witte JJ. Benefits due to immunization against measles. Public Health Reports 1969; 84: 673-80.

25 Willems JS, Sanders CR. Cost-effectiveness and costbenefit analyses of vaccines. F Infect Dis 1981; 144: 486-93.

26 Koplan JP, White CC. An update on the benefits and costs of measles and rubella immunization. In: Grunberg EM, disorders: progress in the conquest of measles and rubella. disorders: progress in the conquest of meas

27 White CC, Koplan JP, Orenstein WA. Benefits, risks and costs of immunization for measles, mumps and rubella. $\mathrm{Am}$ costs of immunization for measles,

28 Ada GL. Vaccines and vaccinations. World Health July 1988, 5-7.

29 Central Bureau of Statistics. Statistical abstract of Israel $1988(24 / 14)$. Jerusalem: Central Bureau of Statistics 1988.

30 Central Bureau of Statistics. Hospitalization data 1979. Special series no. 803. Jerusalem: Central Bureau of Statistics 1987.

31 Krugman S, Katz SL. Infectious disease of children. St Louis: CV Mosby $1981 ; 149-55$.

32 Nelson WE, ed. Textbook of pediatrics. WB Saunders Company. Philadelphia 1979, 859-62.

33 Central Bureau of Statistics. Causes of death 1979. Special series no. 750. Jerusalem: Central Bureau of Statistics 1977.

34 Tulchinsky TH, Abed Y, Ginsberg G, et al. Measles in Israel, the West Bank and Gaza: current status, methods, costs and benefits of eradication. Rev Infect Dis 1990 (in press). 